\title{
Building a Digital Information Platform for Protecting Changbai Mountain Intangible Cultural Heritage
}

\author{
Jing Shi Yang ${ }^{1, a^{*}}$, Yan Feng Chen ${ }^{2, b}$ \\ ${ }^{1}$ Library.Tong Hua Normal University, China \\ ${ }^{2}$ College of Mathematics.Tong Hua Normal University, China \\ awenjianke2007@163.com, byfchenth@126.com
}

Keywords: Changbai Mountain; Intangible cultural heritage; Digital information platform; Information resources

\begin{abstract}
Building a digital information platform has important significance for protecting Changbai Mountain intangible cultural heritage,building the platform must follow some rules,structure design modular and realization procedure of digital information platform are given based on the contents. Finally,the paper analyses some problems which exists building digital information platform. The platform division,technical parameters are also discussed here.
\end{abstract}

\section{Introduction}

Changbai Mountain intangible cultural heritage has a long history and many existing form, it is also the colorful and local characteristics culture which Changbai Mountain Area people have created in their practice. Changbai Mountain intangible cultural heritage has main features,such as distinctive characters, the rich nationality, strong atmosphere frontier resistance, strong internationalism and developing intake, all was determined by the unique geographical environment, complex ethnic composition and frequent domestic and foreign exchanges[1].

These cultural heritage natural, antique, original, true, and so on. Researching and developing ChangbaiMountain intangible cultural heritage has important significance,but the work for protecting them has not achievemets goals, some new means should be applied to intangible culture protection and inheritance.

Digital technology was created with the development of network information technology, it refers to modern multimedia and information technology together. Digital technology is different from traditional save mode, it is an effective mean for protecting intangible cultural heritage.

\section{Changbai Mountain intangible cultural heritage digital information platform content}

Folk art information resources. Changbai Mountain Area is the birthplace of Manchu. Along with immigration in the later Qing dynasty, There was a symbiosis cultural phenomenon came into being between Manchu and other ethnic, the mode of production which people relied on also changed. All ethnic groups inherits living folk intangible culture-including Manchu paper-cut, Manchu embroidered pillow top, Manchu Folk Clay, Manchu folk house, Cloth sticker, Muppet, New Year pictures, Folk oil painting, Local drama, Northeast ballad, Shaman dance, Shaman music, Forest song and Root art[2]. These art form are the visible representation of traditional culture, at the same time,they are the most receptive part,for people.In fact, they have important historical value, artistic value and development value.

Folklore information resources. Changbai Mountain Area has rich folklore heritage, includes traditional myth, legend, story, ballad proverb, etc. Not only from "ShanHai Ching" which appeared before 2300 years ago, to "The book of songs" and "Historical records", but also go through Tang Song Yuan Ming Qing Dynasties[3], Changbai Mountain myth, legend continues today, can be called wonders of Chinese folk literature. Folk tales make an impressive sight, yet mining up, the largest number of local legend, plant story and animal story among them. Especially the story of Changbai Mountain ginseng, it is the representative of Changbai Mountain traditional oral literature, 
ginseng story, dig ginseng customs and ginseng poetry together constitute Chinese ginseng culture, and they make the cultural taste of Changbai Mountain folk tales have more features, aesthetic value and cultural value[4].

Traditional skills information resources. Changbai Mountain Area has vast quantities of natural resources. The people of all ethnic groups carry on manual production labor, for example,

pharmacy, burnt wine, bark, press oil, coaldust leak when they cut wood, split stone, dig ginseng, hunt and farm, these traditional folk crafts are inherited from oral teaching, passes on from generation to generation, form rich religious custom, aesthetic custom and colors custom, all the customed have important folklore value because they are the precipitation of Changbai Mountain Area people's spirit and material life[5].

\section{Changbai Mountain intangible cultural heritage digital information platform design}

Platform need analysis. The main function of Changbai Mountain intangible cultural heritage digital information platform is make all information into digital resources through using digital technology, preserved by high-performance storage devices, then provide personalized service for users by the internet, so the needs for platform can be determined according to the related users.

The needs are users needs and system administrator needs.

Users needs includes four aspects. First, quick understanding a simple overview of Changbai Mountain intangible cultural heritage. Second, using search engine retrieves title, keyword, abstract and author of information resources. Third, information resources' upload/download needs, users can directly put the required resources to download to a local file system, can also sent their own resources to the server for all the users to share. Fourth, the needs of resources' Evaluation, The users can contact the administrator through the message.

System administrator needs includes six aspects. First, dynamic managing platform resources, add, modify, delete all kinds of information resources. Second, managing program, manage the name and rank of various column. Third, audit resources, audit and manage the resources which the users uploads. Fourth, control access permissions. Fifth, verification management, audit registered users and verify their identity. Sixth, users management, Forced locking and delete illegal users, assist users to modify the information[6].

Platform structure design. Combined with the results of needs analysis, Changbai Mountain intangible cultural heritage digital information platform can be divided into three groups,introduction platform, users application platform and administration platform, relying on the DESi characteristic resources construction system, developing dynamic website model database platform.( Fig. 1)

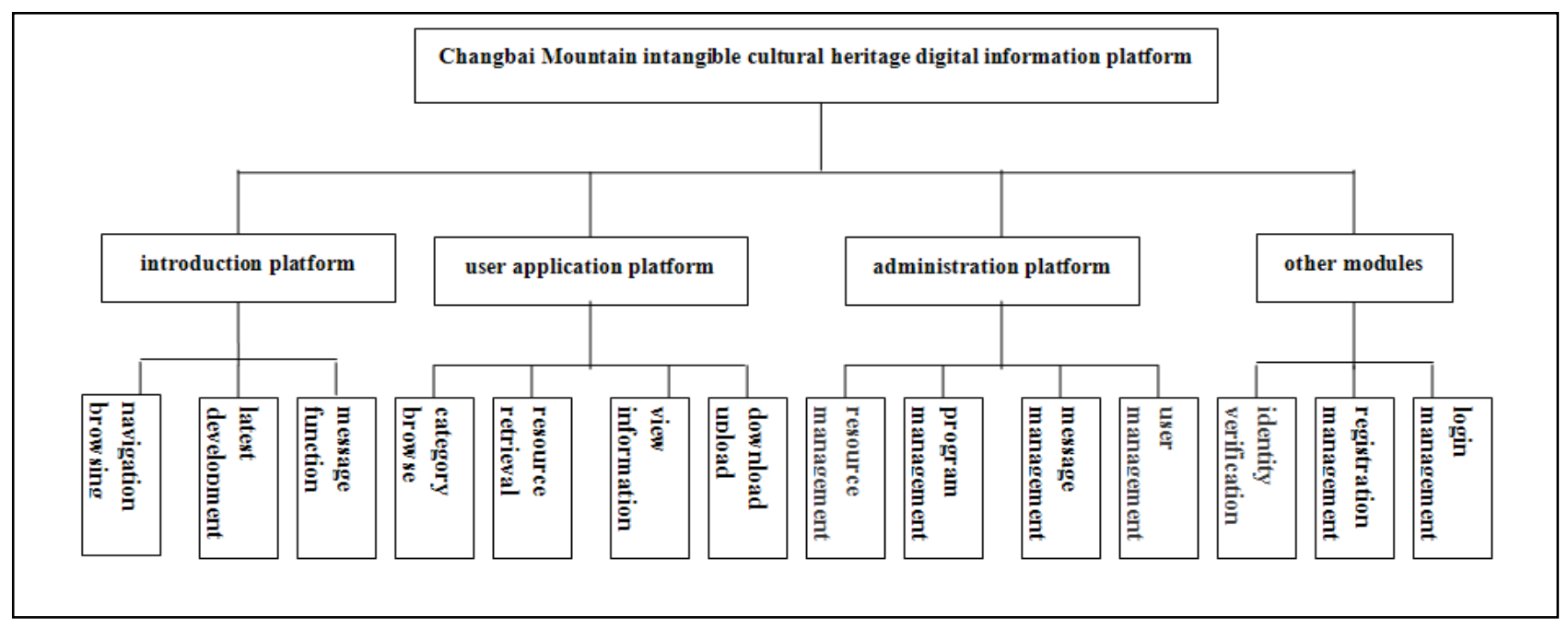

Fig. 1 Changbai Mountain intangible cultural heritage digital information platform structure design 
Introduction platform includes following modules. The first, navigation browsing, introduce intangible cultural heritage background, craft characteristics and show case. The second, latest development, display Changbai Mountain intangible cultural heritage research dynamic by the latest news. The third, message function, various types of users interaction.

Users application platform includes following modules. First, category browse, according to the set column classification browse information resources of Changbai Mountain intangible cultural heritage. Second, resources retrieval, according to the title, abstract, keywords, author of retrieved items retrieved.Third, view information, see the title, abstract, keywords, author brief information. Fourth, download/upload resources, save the information resources to the local, and upload resources to the server to share.

Administration platform includes following modules. First, resources management,add, modify and delete information resources. Second, program management, add, modify and delete various column.Third, message management, review and respond to users message. Fourth,users management,

lock or delete illegal users, set up different levels of users permissions[7].

Other modules includes following modules. First, identity verification, provides authentication based on users roles. Second, registration management, assist the users personal information registration and necessary tips. Third, login management, manage the users login system platform, set up permissions as input the users name, password, check code is not correct, assist the users to change the password.

\section{Changbai Mountain intangible cultural heritage digital information platform realization}

Substantive consolidation stage. The main work is collecting and classifying information resources in the substantive consolidation stage. Changbai Mountain intangible cultural heritage information sources can be divided into five categories. These non material cultural heritage information resources can from nature,folk, academics, industry and government departments.In the process of collecting information resources, Ensure the collected information integrity, coherence, authenticity, continuity and authority is based on clear acquisition department, target acquisition and collection content[8].

Digital stage. There are three aspects in this stage, they are digital conversion, information resources processing and information resources organization,three aspects are synchronized.

The main content of digital conversion is converting all kinds of information resources which recorded in traditional carrier to digital information resources through image processing conversion.

The digital processing of paper document (folklore, murals of literature,etc) and photo ( paper-cut, embroidery, dress, architecture, etc) is scanned or photographed by scanners, digital cameras and other equipment. The digital processing of minicard (non material cultural heritage microfilm existing) is scanned by scanners. Digital equipment for sound recording( folk music, local operas,etc) is audio data acquisition card. And the digital equipment of video ( folk dance, original ecological lifestyle, etc ) is video capture card, the output of device and video recording links up computers through the transmission line.

The key problem of this stage is the choice of technical parameters, original information fidelity, clear and accurate is the priority among priorities. At the same time, pay attention to users convenience, digital information should facilitate the transmission, browse, in order to meet the needs of different users. Scanning image specifications are 300dpi, gray or color mode, TIFF format, it can provide online use after turns 300dpi into $150 \mathrm{dpi}$ or $72 \mathrm{dpi}[9]$. ( Table 1)

Table 1 Guide for the selection of technical parameters

\begin{tabular}{|l|l|l|l|}
\hline $\begin{array}{l}\text { technical } \\
\text { parameters }\end{array}$ & $\begin{array}{l}\text { original version } \\
\text { (save version) }\end{array}$ & browse version & preview version \\
\hline $\begin{array}{l}\text { image resolution } \\
\text { ratio }\end{array}$ & $\begin{array}{l}\text { long side } 300 \mathrm{dpi} \\
-1600 \mathrm{dpi}\end{array}$ & $150 \mathrm{dpi}$ & $72 \mathrm{dpi}$ \\
\hline
\end{tabular}




\begin{tabular}{|l|l|l|l|}
\hline size dimension & $\begin{array}{l}\text { same with the } \\
\text { original }\end{array}$ & long side 600 pixel & $\begin{array}{l}\text { long side 100 pixel } \\
-200 \text { pixel }\end{array}$ \\
\hline color darker & $\begin{array}{l}\text { 1bit monochrome } \\
8 \text { bit gray } \\
24 \text { bit color }\end{array}$ & $\begin{array}{l}\text { 1 bit monochrome } \\
8 \text { bit gray } \\
24 \text { bit color }\end{array}$ & $\begin{array}{l}1 \text { bit monochrome } \\
8 \text { bit gray } \\
8 \text { bit index color } \\
24 \text { bit color }\end{array}$ \\
\hline file format & TIFF & JPEG & JPEG、GIF \\
\hline compression & $\begin{array}{l}\text { lossless } \\
\text { compression }\end{array}$ & $\begin{array}{l}\text { JPEG,Medium } \\
\text { quality compression }\end{array}$ & $\begin{array}{l}\text { JPEG,low quality } \\
\text { compression }\end{array}$ \\
\hline
\end{tabular}

Digital processing for images and multimedia need to pay attention to many problems. The first are the proofreading and correction of digital image, check image correctness, integrity and clarity, check missing page, repeat page, missing words, few words, then modify the content. Of course,the specific work also includes compression, definition, decontamination, distinguishing the text in the image by using the optical identification ( OCR ) technology, transforming raster images to vector graphics through vectorization technology, and so on. Automatic the file system using scanning method, artificial joint graph using digital photography, embedding watermark on the digital information resources with independent intellectual property rights, protecting intangible cultural heritage digital resources' intellectual property, all these operation can make digital information resources into digital image that can be provided to the actual users.

Digital information resources organization is cataloging, Creating a directory and index, Hanging the content and the index. Description is database intelligence control methods, in relation to check and maintenance work difficulty of the digital information platform. The object data processing must strictly follow metadata standard and description rule, multiple object data can be corresponding to a metadata, each object has a unique identity data in information platform. The field type and attribute of journal papers, dissertation, conference papers, e-book, video and audio, internet resources, selected must according to the readers' retrieval habit, description of project options are title, keyword, abstract,author, ISBN/ISSN,language, store location and exact formats,etc.

Application stage. There are many ways to use information resources, users can link click characteristic database of library homepage, log on to Changbai Mountain intangible the cultural heritage digital information platform, through search the related words, use "resources search", "advanced search", "cross database retrieval"functions, access to relevant information resources.

Changbai Mountain intangible cultural heritage digital information platform executes system function through the system on connecting the image file, directory, normative documents, provides retrieval,then controls access. In order to facilitate the transmission utilization the digital information resources characteristics. Digital resources can announced the network, provides online application service, users shares the internal LAN. Online service mode of digital image is divided into free and paid. Provided free of charge is online catalog search and browsing of small size, low resolution image, if users want to use the original size, high resolution image, they need to apply for a pay per use[10].

Changbai Mountain intangible cultural heritage digital information resources and directory information should be preserved for a long-term,updated in real time.

\section{Conclusions}

Changbai Mountain intangible cultural heritage digital information platform construction is a long-term system engineering, need to continue in-depth folk life, continue to tap the information of all kinds of intangible cultural heritage, using digital means to record and keep the true face. Although there are a lot of Changbai Mountain intangible cultural heritage have been inscribed on the world stage, national, provincial, city level intangible cultural heritage project, get overall 
protection, but the others survival environment worsening, the protection of these intangible cultural heritage brooks no delay.

\section{References}

[1] D.H.Chen, Jilin province non - material cultural heritage database research, Library Research, vol. 23(2012), pp. 38-42.

[2]T.T.Luo, Review of productivity protection research of intangible cultural heritage in China, Journal of Tonghua Normal University, vol. 3(2014), pp. 23-26.

[3]X.X.Deng, On the basic of legal protection of intangible cultural heritage of minorities --Taking the example of the Salar, Journal of Tonghua Normal University, vol. 5(2014), pp. 24-26.

[4]B.M.Cao, Effective way to the development and mining for intangible cultural heritage, Journal of Tonghua Normal University, vol. 7(2014), pp. 25-29.

[5]G.Q.Qu, A collaborative innovation: the effective path of inheritance and protection of intangible cultural heritage in Jilin province,Journal of Tonghua Normal University, vol. 3(2013), pp. 27-29.

[6]G.Q.Qu,An innovation strategy inheritance and protection of intangible cultural heritage in Jilin province, Journal of Tonghua Normal University, vol. 7(2013), pp. 23-26.

[7]X.W.Sheng, Introducing the thoughts of intangible cultural heritage of the culture in university campus, Journal of Tonghua Normal University, vol. 7(2013), pp. 27-29.

[8]L.Y.Zhao, The Manchu digital protection platform of intangible cultural heritage research and application, Journal of Tonghua Normal University, vol. 5(2014), pp. 21-23.

[9]H.L.Chen, On the participation for Changbai Mountain intangible cultural heritage protection work of University Library, Journal of Tonghua Normal University, vol. 6(2014), pp. 130-131.

[10]X.F.Xue, Construction of Changbai Mountain folk culture digital archives management platform, Journal of Tonghua Normal University, vol. 6(2014), pp. 132-134. 